\title{
Transtextualidad en la narrativa de Javier Marías*
}

Fecha de entrega: 2 de junio de 2017

Fecha de evaluación: 26 de julio de 2017

Fecha de aprobación: 11 de agosto de 2017

\author{
Jorge Iván Parra**
}

\section{Resumen}

El presente ensayo pretende mostrar cómo la obra novelística de Javier Marías puede ser vista a la luz de la teoría de Gérard Genette sobre la transtextualidad, es decir, lo que también se conoce como palimpsesto (de ahí el título de su libro, Palimpsestos, la literatura en segundo grado). Se mostrará que dicha transtextualidad se da principalmente entre las novelas Mañana en la batalla piensa en mí, Corazón tan blanco y Negra espalda del tiempo y las obras de Shakespeare, Ricardo III, Macbeth y La tempestad, respectivamente, producto, tal vez, de la conocida anglofilia de Marías.

Palabras clave: palimsesto, intertextualidad, hipertexto, hipotexto, anglofilia, roman á clef.

* Ensayo. DOI: http://dx.doi.org/10.15332/s0120-8462.2017.0117.09

* Licenciado en educación de la Universidad del Tolima. Magister en Literatura del Instituto Caro y Cuervo; Magister en Filosofía Latinoamericana de la Universidad Santo Tomás. Especialista en Psicolingüistica de la Universidad Distrital y Especialista en Crítica Literaria de la Universidad del Rosario. Profesor de la Maestria en Estudios Literarios USTA. Articulista del diario El Tiempo. 


\title{
Transtextuality in the narrative of Javier Marias
}

\author{
Jorge Iván Parra
}

\section{Abstract}

This essay aims to show how Javier Marías' novelistic work can be seen in the light of Gérard Genette's theory about transtextuality, that is, what is also known as palimpsest (hence the title of his book, Palimpsests, literature in the second degree). It will be shown that this transtextuality occurs mainly between the novels Tomorrow in the battle think of me, A heart so white y Dark back of times and the works of Shakespeare, Richard III, Macbeth and The Tempest, respectively, resulting, perhaps, of the well-known Anglophilia of Marias.

Keywords: palimpsest, intertextuality, hypertext, hypotext, anglophilia, roman a clef.

\section{Transtextualidade en la narrativa de Javier Marías}

\author{
Jorge Iván Parra
}

\section{Resumo}

O presente artigo pretende mostrar como a obra novelística do Javier Marías pode ser vista à luz da teoria de Gérard Genette sobre a transtextualidade, aliás, o que também se conhece como palimpsesto (daí o título do seu livro, Palimpsestos, a literatura em segundo grau). Se mostrará que esta transtextualidade acontece principalmente entre os 
romances Mañana en la batalla piensa en mí, Corazón tan blanco e Negra espalda del tiempo e as obras do Shakespeare, Ricardo III, Macbeth e A tempestade, respectivamente, produto, talvez, da conhecida anglofilia do Marías.

Palavras-chave: palimpsesto, intertextualidade, hipertexto, hipotexto, anglofilia, roman á clef.

\section{La teoría de Genette}

Este ensayista francés es uno de los más influyentes en la denominada ciencia literaria o en los estudios literarios, tanto como lo son Bajtín, Greimas y Kristeva, sin descartar a Umberto Eco. Se dio a conocer en 1972 con su Discours du récit, texto que explica los diversos procedimientos (o sea, la acción verbal a la que llamamos narración) en que una historia (histoire), el acontecimiento narrado, se convierte en relato (récit). Texto narrativo oral o escrito, ya concluido. Dichos procedimientos son el objeto de estudio de la llamada narratología, cuya formulación suele atribuirse, antes que a Genette, a Mieke Bal.

La teoría de la transtextualidad o trascendencia textual del texto (todo lo que pone al texto en relación, manifiesta o secreta, con otros textos) fue formulada por su autor en 1981, pasada por nuestro cedazo, en los siguientes términos: leer un texto teniendo en cuenta, descubriendo su relación con otros textos, es el objeto de la poética, mientras que leerlo considerado en su singularidad, es asunto de la crítica. La primera lectura (más literaria) produce la significancia; la segunda, el sentido.

No todos los diálogos o relaciones que se dan entre los textos constituyen una intertextualidad, pues esta es tan solo un tipo de relación textual que se puede dar así: 1) por simple copresencia o presencia efectiva de un texto en otro, 2) por la práctica tradicional de la citación (entre comillas, con o sin referencia precisa), 3) por préstamo no declarado pero literal, esto es, el plagio, y 4) simplemente por alusión.

Lo anterior implica la ocurrencia de otros tipos de relaciones entre textos. Tal es el caso de la paratextualidad, o sea, la relación que el texto propiamente dicho mantiene con lo que no se puede llamar más que un paratexto: título, subtítulo, intertítulos, prefacios, advertencias, post-facios, introducciones, notas marginales, epígrafes, ilustraciones, 
apostillas, sobrecubierta y demás tipos de señales accesorias, autobiográficas, que dan al texto un contorno. Piénsese, como ejemplo, en las portadas y títulos de las novelas de aventuras, que prácticamente nos dicen de qué tratan; verbigracia: El conde de Montecristo o La isla del tesoro, donde su relación es evidente; mientras que en novelas como El nombre de la rosa, de Eco, o El sentido de un final, de Barnes, sus autores han pretendido que la paratextualidad no se dé en forma explícita, pues el lector tiene que buscar una interpretación del título, una relación con el contenido, que en la mayoría de los casos no la encuentra. Hay casos como el de Roberto Bolaño, quien titulaba las novelas, prácticamente para engañar al lector respecto a su contenido. La literatura nazi en América, y El tercer Reich, como títulos son puro despiste, y un título como 2666 plantea todo un reto a la hora de interpretarlo.

Otro tipo de transcendencia textual es la metatextualidad o relación de comentario que une un texto a otro del cual habla; es por excelencia la relación crítica, muy común en autores como Borges, en cuyo caso un texto puede estar relacionado con otro a través de la ficción misma, como en el cuento "Pierre Menard autor del Quijote". Tipo de relación que se puede apreciar más recientemente en la novela Bravura de Emmanuel Carrére, toda ella referida a Frankenstein de Mary Shelley.

Una clase de trascendencia textual más abstracta y más implícita es la architextualidad, en la que el autor ( $y$, a veces, el editor) orienta y determina lo que Jauss denomina "horizonte de espera del lector", mediante títulos tales como Antología de la poesía francesa, de Andrés Holguín; Poesía y poetas colombianos, de Fernando Charry Lara, $\mathrm{y}$, en general todas las selecciones, recopilaciones y antologías. Los subtítulos o infratítulos como indicaciones de novela, relato, poesía, etc., que acompañan al título en la portada, etc.; ej.: La mansión de Araucaíma, Novela gótica de tierra caliente, de Álvaro Mutis.

El tipo de diálogo textual más común y más literario quizá es el de la hipertextualidad, en el que un texto se construye con base en (o como continuación de) otro. En ese caso, el texto derivado es el hipertexto, y el texto modelo es el hipotexto; es la trascendencia textual que se da entre La Odisea y Ulises de Joyce, o entre Don Quijote y Capitulos que se le olvidaron a Cervantes. En realidad, son transformaciones que se pueden dar en forma simétrica (decir la misma cosa de otra manera, como hace García Márquez en Memorias de mis putas tristes, una especie de reformulación de La casa de las bellas durmientes, de Kawabata) o inversa (decir otra cosa de la misma manera, como hace Murakami en "Samsa enamorado", cuento en el que un insecto 
amanece convertido en un horripilante ser humano) y que, al fin y al cabo, establecen los límites entre el arte y el Kitsch: entre la creación y la imitación.

Vemos, pues, que ante la multiplicidad de transferencias textuales que se pueden dar es necesario acudir a un solo término genérico que las englobe a todas y que de hecho nos saque de apuros cuando se den simultánea o sucesivamente en un mismo texto, como en los casos de Terra Nostra, la monumental obra de Carlos Fuentes, y aun en relatos cortos como el mencionado "Pierre Menard", de Borges. Este término genérico es el que Genette nos ha formulado con el nombre de transtextualidad y que si bien es cierto se trata de un efecto de la literatura, también es cierto que no se materializa sin la percepción del lector. Esto último es muy importante, porque la transtextualidad no es algo inmanente, y así lo explica el mismo Genette:

el texto en sí mismo no está a conocer, y mucho menos a declarar, su cualidad genérica. La novela no se designa explícitamente como novela, ni el poema como poema. Todavía menos quizá (pues el género es sólo un aspecto del architexto), el verso como verso, la prosa como prosa, la narración como narración, etc. En último término, la determinación del estatuto genérico de un texto no es asunto suyo, sino del lector, del crítico, del público, que están en su derecho de rechazar el estatuto reivindicado por vía paratextual. Así, se dice corrientemente que tal tragedia de Corneille no es una verdadera tragedia, o que Le Roman de la Rose no es una novela. (Genette, 1989, p. 13)

En resumen, son cinco los tipos de relaciones transtextuales propuestas por el crítico francés: 1) intertextualidad, 2) paratextualidad, 3) metatextualidad, 4) hipertextualidad, y 5) architextualidad. Cabe anotar que estas relaciones no son estáticas, sino dinámicas (como lo vamos a ver a continuación con respecto a Marías) y que este dinamismo depende no solo de la percepción, sino de la cultura literaria del lector.

\section{Un anglófilo que sabe jugar con Shakespeare}

Mi primer feliz encuentro con la prosa de Marías fue precisamente de tipo intertextual: me cayó a la mano un libro que inevitablemente me remitió a la obra de Shakespeare que más admiro, Ricardo III. Fue un reflejo condicionado, ya que distingo fácilmente cualquier diálogo, escena o monólogo de ese drama histórico. Este título viene de Shakespeare, me dije; "Mañana en la batalla piensa en mí”, es una expresión, una 
premonición y una amenaza que se repite varias veces en el último acto de Ricardo $I I I$ y, en consecuencia, es como una especie de texto de origen, si no de la novela de Marías, sí del título.

La novela no tiene nada que ver directamente con el drama isabelino. Con ella, su autor ganó el premio "Rómulo Gallegos"; el "Fastenrath de la Real Academia"; el premio “Arzobispo Juan de San Clemente"; y el "Prix Femina E Tranger”, no más haberla publicado en 1994 .

¿Cuál es la histoire de Mañana en la batalla piensa en mí, y qué interpretación se le puede dar?

En once capítulos, de esos que de verdad se leen con fruición, en razón al suspenso que crean y a la fluidez de la escritura, Marías presenta todo un tratado sobre el engaño, una temática constante en todas sus obras, ya que según él, "vivir en el engaño es fácil y nuestra condición natural". Martha, una mujer adúltera (los adúlteros son personajes recurrentes del autor) en ausencia de Deán, su marido, trae a su apartamento y mete en su cama a Víctor, su amante y narrador del episodio; como tienen que esperar a que el pequeño hijo de aquella se duerma, momentáneamente dormitan acostados de lado, ella dándole la espalda a su amante y después de expresar casi intrascendentemente "No me siento bien, no sé qué me pasa" y un poco más extrañamente "Ay Dios, y el niño", Martha se muere y Víctor tarda bastante rato en darse cuenta. Después vendrá el lío de qué hacer con la muerta, qué hacer con las llamadas de su marido en el contestador, qué va a pasar con el niño cuando se despierte y qué va a ser de la suerte del narrador. Pero no será la única muerte absurda en la novela (como tampoco será la única novela de Marías en la que ocurran muertes absurdas). Dado que es una novela de engaños mutuos y encadenados, y de muertes, "la batalla" es el diario que le espera a cada personaje después de sus duras experiencias. Ninguno podrá vivir sin batallar contra la sordidez de sus recuerdos.

“Mañana en la batalla piensa en mí”, puede ser lo que el recuerdo o la voz de cada muerta dejen en la memoria y en la conciencia de Víctor y Deán.

Esta expresión es lo que golpea la conciencia de Ricardo III, la víspera de su batalla decisiva contra Richmond en Bosworth, por la corona de Inglaterra. Uno a uno los espectros de las víctimas de Ricardo se le aparecen en el sueño y lo intimidan: "Medita 
en mí mañana, durante el combate... ¡desespérate y muere!” “Tomorrow in the battle think on me... Despair, and die"! (Shakespeare, Ricardo III, 1988, p. 883).

Varias veces aparece intercalada en soliloquios y monólogos del narrador la frase tomada de Shakespeare; la primera de ellas cerrando el primer capítulo, "Mañana en la batalla piensa en mí”, pensé; o más bien me acordé de ello (Marías, 1997, p. 38); la segunda, "Mañana en la batalla piensa en mí, y caiga tu espada sin filo: desespera y muere", en la página 51; pero hay un episodio en que la alusión a Ricardo III es muy clara y con ella también muy clara la intención de Marías de jugar con los textos del "Cisne del Avon”. Una noche, tras llegar tarde a su casa, Víctor, como quien no quiere la cosa, prende el televisor y lo primero que ve en el canal es a un caballero con armadura que encomendaba su alma a Dios de rodillas ante una tienda de campaña y, en contrapunto, otro hombre acostado y vestido como un rey, que padecía insomnio, en otra tienda de campaña. En ningún momento el narrador da nombres; pero es evidente que son Richmond (futuro Enrique VII) y Ricardo York (en el momento, usurpador de la corona).

Y entonces le fueron apareciendo, uno tras otro, fantasmas sobreimpresionados en un paisaje, tal vez el campo de una futura o inminente batalla: un hombre, dos niños, otro hombre, una mujer y otro hombre, por último, que agitaba los puños en alto y solo gritaba como quien clama venganza [...] le decían cosas horribles con las voces tristes de quienes han sido traicionados o muertos por aquel que amaban: “Mañana en la batalla piensa en mí”, le decían los hombres y la mujer, y los niños, uno tras otro, "y caiga tu espalda sin filo: desespera y muere" [...], y ese rey se incorporaba o despertaba aterrado chillando tras estas visiones de la noche horrenda y yo también me espanté al verlas y al oír su aullido desde la pantalla; sentí un escalofrío - es la fuerza de la representación, supongo. (Marías, 1997, pp. 276-277)

Y el narrador cambia el canal porque ni sabe ni entiende lo que está viendo; pero Marías nos ha puesto frente a la pantalla para que entremos en el jueguito que nos propone, como lo habría de hacer en su primera novela Los dominios del lobo, en el que varios episodios son la reproducción de lo que el narrador ve en el cine. ¿Qué tipo de transtextualidad se da en este episodio? Puede resultar algo complejo (ya dijimos que es algo dinámico, no estático), dado que el narrador no está citando el texto de Shakespeare, solo describe lo que el personaje está viendo, y ni este ni aquel 
saben lo que están mirando. En consecuencia, es la percepción (y la cultura literaria del lector) la que determina qué es lo que personaje y narrador tienen ante sus ojos. En ese caso se podría hablar de hipertextualidad, dado que en un texto B (la novela) se inserta un texto A (la película) derivada a su vez de un texto anterior, que deberemos llamar hipotexto (la obra teatral original), es decir, hay todo un palimpsesto. Pero también, si nos atenemos a las imágenes en pantalla, por aquello de que se da la presencia efectiva de un texto (el drama shakespereano) en otro (la novela de Marías), la relación que se da es la intertextualidad. ¿Hay necesidad de que el lector se embrolle con esto para entender la novela? Claro que no. Una cosa es leer una novela para saber de qué se trata, para disfrutar su trama, y otra, leerla para descubrirle las costuras o para descubrir la literariedad (término de Genette) de aquella; para ver por qué Marías juega con Shakespeare.

Shakespeare habrá de servirle a Marías para más: el título de su novela Corazón tan blanco, también proviene del reportorio del dramaturgo inglés y nada menos que de Macbeth. En la segunda escena del segundo acto, tras consumarse el crimen contra Duncan, Lady Macbeth advierte la turbación de su esposo por convertirse en asesino, y para involucrarse más y repartirse la responsabilidad con Macbeth y simular que ha cometido el crimen, se unta las manos de sangre (la de Duncan que Macbeth tiene en las suyas) y le dice: "My hands are of your color, but I shame to wear a heart so White." "Mis manos son de tu color. Pero me avergonzaría de tener un corazón tan blanco" (Shakespeare, La tragedia de Macbeth, p. 507).

Volvemos con el tema de la transtextualidad para señalar que el título de la novela de Marías es hipertexto del drama de Shakespeare en la medida en que tiene su origen en la expresión mencionada. Pero en rigor, el contenido tiene poco que ver, salvo porque en la novela del español hay un crimen cuyo misterio se resuelve apenas al final y el personaje que lo descubre termina involucrándose (a fuerza de enterarse), es decir, renunciando a su inocencia frente al hecho.

Corazón tan blanco (1992) le mereció al autor el premio de la Crítica/93; el Prix l'oel et la Lettre/93 y el IM PAC international ublin Literary Award/97 y ha sido publicada en más de treinta países. Esto intrínsecamente no comporta el valor de su novela; pero a lo mejor es síntoma de su calidad. La obra de 16 capítulos (el $15^{\circ}$ aclara el $1^{\circ}$ ) nos termina diciendo que el corazón tan blanco es el de quien todavía no sabe lo que no debería saber, es el corazón aún no manchado, que lo estará tan pronto la persona escuche lo malo que otros han hecho, los secretos que nunca deben revelarse (como 
cuando Macbeth, después de asesinar a Duncan, le dice a su esposa "ya está hecho el hecho", "ya lo hice").

Así se echó a perder el "corazón tan blanco" de Teresa Aguilera (lo que habilita una forma de paratextualidad, porque el título se llena de sentido y la novela de significancia), la tía del narrador Juan Ranz, cuando su esposo le confiesa haber matado a su primera esposa, para poder casarse con ella. Lo peor es que alguna vez Teresa dijo, descuidadamente, que mientras aquella estuviera viva sería imposible la vida con Ranz (padre del narrador en su tercer matrimonio, esa vez con la hermana de Teresa). Teresa se suicida nada más conocer el secreto (aquí cabe decir que Lady Macbeth, poseedora del secreto de la muerte de Duncan, también se suicida). Sabe que su corazón ya está manchado como el de Lady Macbeth. Es el inicio de la novela y también su asunto; pero el motivo solo lo conoceremos al final de esta, cuando Ranz, cuarenta años después de su crimen hasta ahora mantenido en secreto, y del suicidio de su esposa, se lo revele a la esposa de su hijo Juan.

Javier Marías nos dice en este libro de bien trabajada prosa, que escuchar puede ser peligroso; que los oídos no tienen párpados y una vez sabido lo que ya es demasiado tarde para no haberse sabido, los corazones se manchan.

Con Marías aprendemos que uno es lo que los demás saben de nosotros; que los hechos pueden quedar en la memoria pero lo que se dice no se borra, y que el hacer es hijo del decir:

No es sólo que Lady Macbeth induzca a Macbeth, es que sobre todo está al tanto de que se ha asesinado desde el momento siguiente al que se ha asesinado, ha oído de los propios labios de su marido 'I have done the deed' cuando ha vuelto, 'He hecho el hecho', o 'He cometido el acto', aunque la palabra 'deed' se entiende hoy en día más como hazaña”. Ella oye la confesión de ese acto o hecho o hazaña, y lo que la hace verdadera cómplice no es haberlo instigado, ni siquiera haber preparado el escenario antes ni haber colaborado luego, haber visitado el cadáver reciente y el lugar del crimen para señalar a los siervos como culpables, sino saber de ese acto y de su cumplimiento. Por eso quiere restarle importancia, quizá no tanto para apaciguar al aterrado Macbeth con las manos manchadas de sangre cuanto para minimizar y ahuyentar su propio conocimiento, el de ella misma: 'Los dormidos, y los muertos, no son sino como pinturas'; 'Aflojas tu noble fuerza, al pensar en las cosas con tan 
enfermizo cerebro'; 'No se debe pensar de esta manera en estos hechos: Así, nos hará locos': 'No te pierdas tan abatido en tus pensamientos'. Esto último se lo dice tras haber salido con decisión y haber regresado de untar los rostros de los sirvientes con la sangre del muerto ('Si sangra...') para acusarlos: 'Mis manos son de tu color', le anuncia Macbeth, 'Pero me avergüenzo de llevar un corazón tan blanco', como si intentara contagiarle su despreocupación a cambio de contagiarse ella de la sangre vertida de Duncan, a no ser que 'blanco' quiera decir aquí 'pálido y temeroso' o 'acobardado'.

Ella sabe, ella está enterada y esa es su falta, pero no ha cometido el crimen por mucho que lo lamente o asegure lamentarlo, mancharse las manos con la sangre del muerto es un juego, es un fingimiento, un falso maridaje con el que mata, porque no se puede matar dos veces y nunca hay duda de quién es 'yo', y ya está hecho el hecho. Sólo se es culpable de oír las palabras, lo que no es evitable [...] la propia vida no depende de los propios hechos, de lo que uno hace, sino de lo que de uno sabe, de lo que se sabe que ha hecho. (Marías 1992, pp. 100-101)

Por la forma como en el párrafo citado vienen intercalados enunciados de La tragedia de Macbeth, la intertextualidad entre la novela de Marías y el drama de Shakespeare, es más que plausible. Y por la forma como el narrador no solo alude, sino que comenta críticamente dicho drama, se da un caso muy ejemplar de metatextualidad. Y si se nos diera por identificar esa voz del narrador que comenta la obra de Shakespeare, directamente con la del autor estaríamos frente a un caso de lo que Genette en una teoría más reciente llama Metalepsis narrativa (Véase, Metalepsis: de la figura a la ficción, Genette, 2004).

Es decir (conclusión adelantada), de que Marías juega con Shakespeare, ni sombra de duda, y de que este juego es perfectamente observable desde la teoría de Genette, tampoco hay duda. También podría verse a la inversa: la obra de Marías nos permite ilustrar y entender, mediante ejemplos concretos, la propuesta teórica de Genette.

Pero el juego literario de Marías con Shakespeare trae aún más sorpresas, pues siguiendo la teoría sobre la transtextualidad, otro título de novela proviene de una cita de la tardía comedia La tempestad. En la segunda y última escena del primer acto, Próspero, quien con su magia hizo naufragar al Rey de Nápoles con todo su séquito, para hacer llegar 
a su isla a Fernando el hijo del rey, sostiene un diálogo con su hija Miranda. En este le cuenta a ella momentos de su pasado que supuestamente por lejanos ella no puede recordar; pero para sorpresa de él sí los recuerda y entonces le pregunta con asombro: “¿Cómo es posible que persista esto en tu memoria? ¿Qué ves aún en las tinieblas del pasado y en la negra espalda y abismo del tiempo? (Shakespeare, La tempestad, p. 982). Marías suprime únicamente la palabra abismo, tal vez porque no está manejando la cita directamente sino como la recuerda en su momento, o tal vez porque de otro modo el título quedaría muy largo y perdería eficacia. Además, "negra espalda” y "abismo del tiempo" pueden interpretarse literariamente como la misma cosa en español.

Negra espalda del tiempo (1998b) se nos antoja un libro novedoso, original, complejo, lúdico. Son veintiún capítulos que conforman lo que el mismo autor denomina "falsa novela" o libro de incisos, que en buena parte se dedica a comentar el libro que por su contenido le sirve de hipotexto, es decir, hace posible su escritura, de él depende. Me refiero a Todas las almas (1988).

La novela discurre casi sin que el lector se dé cuenta, un poco al estilo de las obras de Macedonio Fernández, pues Javier Marías se presenta como autor-narrador, para ayudar o instar al lector al discernimiento. Esto debido a que Todas las almas se prestó para espurias identificaciones de personajes, situaciones y hasta del mismo narrador, con posibles correlatos en la vida real. La propuesta literaria de Marías es sumar anécdotas aparentemente inconexas; recordar episodios enteros de otras novelas (para lo cual copia páginas textuales); convertir datos biográficos en pequeños relatos, que más parecen de la ficción que de la realidad; inventar vidas paralelas cuya verosimilitud es apoyada con fotos, recortes de periódicos, mapas, etc., que le sirven de paratexto. Por ejemplo, rescata del anonimato literario a dos escritores ingleses (y por ello también lo de su anglofilia): John Gawsworth (el mismo de Todas las almas) y Wilfrid Ewart, cuya vida y muerte fueron tan novelescas que hacen dudar al lector ( $\mathrm{y}$ de hecho es el objetivo de Marías "la novela en clave") de si lo que dice de ellos es real o pura invención.

La expresión "la negra espalda del tiempo" es el revés del tiempo, lo pasado o lo transcurrido; es el improbable lugar en el que permanece el recuerdo, lo imaginado, lo que ya pasó y lo que sucederá. Es el tiempo de lo novelesco, el de los muertos y los no nacidos.

La historia en parte inventada de John Gawsworth es fascinante, es la historia de un escritor absolutamente olvidado, a pesar de haber sido elogiado por él mismo Conan 
Doyle, que hereda el reino de Redonda (una isla tan ignorada como su dueño, pero que Marías ubica perfectamente en un mapa anexo y hasta da las indicaciones para llegar), pero nunca toma posesión. Sin embargo, su título nobiliario y su virtual poder y su riqueza lo enajenan; se entrega al muy noble e inglés hábito del alcohol y termina al cabo de varios años como un mendigo de los muchos que Marías, o bien vio, o bien creó en el Oxford de las novelas.

Episodio bien tragicómico es en el que el escritor rey-mendigo ve uno de sus libros en la librería de viejo, cotizado a un precio exorbitante y ni el dueño de la librería ni los mendigos circunstantes que también andan botella en mano, le creen, cuando él les jura y les grita con emoción, con angustia y con rabia que es su autor; el librero le espanta como a un desquiciado y los mendigos creen que son efectos de la sempiterna borrachera en la que anda. Como la obra de Javier Marías es un entramado de textos, ese es el tema de su cuento de 1989 "Un epigrama de lealtad".

Sobra decir que la lectura de Negra espalda del tiempo pierde todo el sentido si previamente no se ha realizado la lectura de Todas las almas, hipotexto de aquella. Novela traducida ya a nueve idiomas y con la que el autor agregó a su larga lista de premios el "Ciudad de Barcelona" de 1989. Nótese que en la relación referida Marías ya no está jugando con Shakespeare, sino con él mismo.

\section{La ambigüedad de la novela en clave (roman á clef)}

Aventurando una interpretación, "Todas las almas" pueden ser las que habitan la memoria del narrador (un trasunto evidente del autor) después de su paso por Oxford como profesor visitante. Para cada alma hay una historia, o al menos un episodio relacionado con los años de vida oxoniense del "español”. La narración centra sus amoríos con Clare Bayes, quien vivía con su marido en Oxford (el engaño que no falta). Ella hace posible la vinculación como personaje de la novela a John Gawsworth, quien fue el amante de la madre de Clare, cuando ella tenía tres años, hasta que ella se suicidó tirándose de un puente en Delhi, ciudad en la que el padre de Clare era diplomático inglés. Gawsworth, el escritor-rey-mendigo, es referido al "español" por un cazador de libros viejos, afición compartida por el "español". Es una especie de personaje ausente, es decir, un alma más entre las que pueblan el hoy de la memoria del narrador. La novela es un retablo de la vida académica de esa "ciudad estática conservada en almíbar" desde cuyo cielo 
la acompaña una "luna pulposa y móvil". Son pues estas dos novelas imbricadas de Javier Marías una muestra del relato en clave por un lado y de la biografía novelada por el otro, si es que acaso no son la misma cosa. El mismo Marías tiene como máximo exponente del género a Thomas Bernhard, pues en sus cinco novelas autobiográficas finge narrar su vida de niño pero todo lo refunde con la ficción, de tal manera que se crea un género ambiguo en el que no se sabe cuál es el margen que separa lo verídico de lo inventado. La estrategia para narrar navegando en dos aguas la explica Marías en su ensayo de 1987 Autobiografía y ficción:

El autor presenta su obra como obra de ficción, o al menos no indica que no lo sea; es decir, en ningún momento se dice o se advierte de que trate de un texto autobiográfico o basado en hechos verídicos. Sin embargo, la obra en cuestión tiene todo el aspecto de una confesión, y además el narrador recuerda claramente al autor, sobre el cual solemos tener alguna información, sea en el propio libro, sea fuera de él. El resultado del malabarismo de esta ambigüedad es tan asombrosa que las sospechas del lector oscilan entre dos polos o tendencias opuestas, sin que pueda decidirse por ninguna de ellas. Por un lado el relato se ofrece como ficción pero en una forma en absoluto ficcionalizada, lo cual le hace desconfiar de esa presunta ficción y pensar que en realidad se trata de un narrador $y$ de una historia que en realidad pueden identificarse con el autor y con su historia. Por otro lado, sin embargo, y una vez que el lector ha decidido que el autor habla de sí mismo y maneja un material "verídico" aunque no lo indique de manera explícita, se encontrará con la permanente sospecha de que el autor esté aprovechando tal creencia para pasarle como "verdadera" una información totalmente ficticia acerca de sí mismo. Una información “inventada”. (Marías, 2001, pp. 77-78)

El hecho de que Javier Marías (Madrid, 1951) haya empezado su carrera como escritor (aunque también es traductor e intérprete de oficio y profesor de letras) a los diecisiete años no significa que sea un genio ni un prodigio; pero sí muestra que no ha improvisado y que muy rápido descubrió y aprovechó su talento, más que nada para componer una obra caracterizada por lo que Genette llama literariedad, sobre todo, como ya se vio, por su forma de jugar con Shakespeare. A su escritura, gracias por ese juego transtextual, por ser todo un fascinante palimpsesto literario, una "literatura en segundo grado". 


\section{Referencias}

Genette, G. (2004). Metalepsis. De la figura a la ficción. Traducción de Luciano Padilla López. México D.F.: Fondo de Cultura Económica.

Genette, G. (1989). Palimpsestos: la literatura en segundo grado. Traducción de Celia Fernández Prieto. Madrid: Taurus.

Marías, J. (1997). Mañana en la batalla piensa en mí. Madrid: Alfaguara.

Marías, J. (1998a). Todas las almas. Madrid: Alfaguara.

Marías, J. (1998b). Negra espalda del tiempo. Madrid: Alfaguara.

Marías, J. (1999). Corazón tan blanco. Madrid: Alfaguara.

Possi, V. (2014). Javier Marías por Javier Marías: autoficción y metanarrativa en “Negra espalda del tiempo" y “Los enamoramientos”. Estudios de Literatura, 5, 148-167.

Shakespeare, W. (1988). Obras completas. Estudio preliminar, traducción y notas de Luis Astrana Marín. Primera versión íntegra del inglés. 2 tomos.

Torres, N. (2016). El camino de la experiencia estética: entre la vivencia y la comprensión. Cuadernos de Filosofía Latinoamericana, 37(114), 103-115. Dor: http:// dx.doi.org/10.15332/s0120-8462.2016.0114.04

Villa, W. (2013). Memoria y pedagogización del mal-decir: una aproximación a los recorridos literarios que inventan mundos. Cuadernos de Filosofía Latinoamericana, 34(108), 79-107. DOI: http://dx.doi.org/10.15332/s0120-8462.2013.0108.03 